\title{
Educação e Metodologias Ativas Inovadoras em Sala de Aula
}

DOI: 10.1590/1809-58442019111

\section{Ingrid Santella Evaristo ${ }^{1}$}

https://orcid.org/0000-0002-1115-3622

\section{Adriana Aparecida de Lima Terçariol ${ }^{2}$}

https://orcid.org/0000-0002-5824-2294

${ }^{1}$ (Universidade Nove de Julho, Centro de Pós-Graduação Stricto Sensu, Programa de Mestrado em Gestão e Práticas Educacionais. São Paulo - SP, Brasil).

${ }^{2}$ (Universidade Nove de Julho, Centro de Pós-Graduação Stricto Sensu, Programa de Pós-Graduação em Educação. São Paulo - SP, Brasil. Universidade Nove de Julho, Centro de Pós-Graduação Stricto Sensu, Programa de Mestrado em Gestão e Práticas Educacionais. São Paulo - SP, Brasil).

\section{CAMARGO, F.; DAROS, T. A sala de aula inovadora:} estratégias pedagógicas para fomentar o aprendizado ativo. Porto Alegre: Penso, 2018.

Metodologia Ativa é o tema central do livro "A sala de aula inovadora: estratégias pedagógicas para fomentar o aprendizado ativo", organizado por Fausto Camargo e Thuinie Daros. Organizado em duas partes - a primeira composta de três capítulos introdutórios e argumentativos; e a segunda focada em estratégias pedagógicas para o aprendizado ativo são descritas quarenta e três estratégias, de maneira sequencial.

O prefácio, escrito pelos autores, destaca, como importantes, as metodologias ativas no processo do aprender,

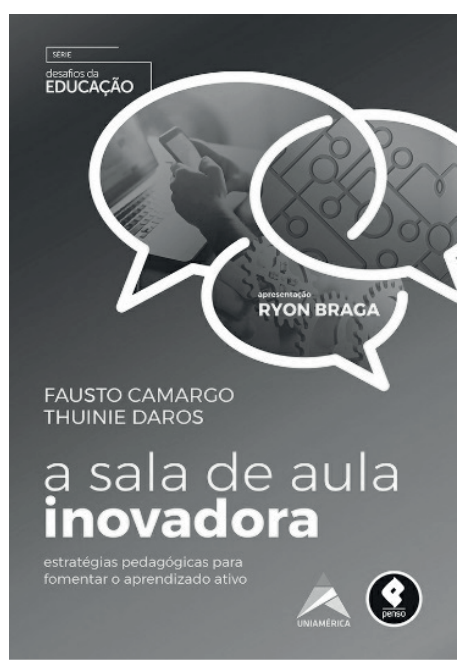
utilizando experiências reais ou simuladas; a resolução de desafios da prática social ou profissional em diversos contextos; o processo formativo do aluno; as competências; possíveis habilidades e competências a serem desenvolvidas nos alunos; sequências didáticas; processo; procedimento, passo a passo da aplicação e uso da estratégia; recomendações; outras maneiras de aplicar e perspectivas complementares às estratégias; exemplos; quadros; tabelas; figuras e recursos possíveis.

A parte I, intitulada "A sala de aula inovadora", apresenta-se dividida em três capítulos. No primeiro, denominado "Por que inovar na educação", Thuinie Daros discute a inovação na educação como essencial e necessária para a transformação, em que o aprender deve acontecer de forma significativa. A autora, mencionando Terra (2007), explana o que 
significa inovar e como inovar na educação, ressaltando que a prática educacional deve ter finalidades bem estabelecidas, mas que é preciso que mudanças partam de questionamentos das finalidades das próprias experiências educacionais como aspecto de promoção da reflexão-ação do docente, por meio da motivação com objetivos de gerar engajamento dos alunos no processo de aprendizagem, fazendo com que esse aluno assuma responsabilidades pelo seu aprendizado e desenvolvimento. Nesse sentido, a autora finaliza apresentando o ensino híbrido como ferramenta para eficiência e personalização das necessidades relacionadas ao ensino envolvente e significativo.

No segundo capítulo, denominado "Metodologias Ativas: aspectos históricos e desafios atuais”, Daros salienta que o aprendizado ocorre se inserido no contexto diário do aluno. Para tal, a autora discorre, brevemente, sobre o histórico da educação e suas propostas, ressaltando que os conhecimentos prévios dos alunos devem ser valorizados para que a aprendizagem seja realmente significativa. A autora, citando Dewey (1976), diz que o pensamento não pode ocorrer isolado da ação, cabendo ao professor apresentar os conteúdos na forma de questões ou problemas e não dar de antemão respostas ou soluções prontas. A autora traz relatos de experiências inovadoras, com aprendizados entre os pares e uma sala de aula invertida, utilizando o pensamento científico, articulado com as novas tecnologias da informação e da comunicação, de forma que o modelo tradicional de ensino não seja o único modelo. Esse capítulo é importante, uma vez que, em um período que muito se fala em tecnologias e nativos digitais, a autora nos remete a reflexões e nos leva a reconhecer a necessidade das metodologias ativas de aprendizagem como alternativa de grande potencial para atender as demandas e desafios da educação atual.

No terceiro capítulo, intitulado "Por que usar metodologias ativas de aprendizagem?”, Fausto Camargo, ao questionar o motivo da utilização das metodologias ativas de aprendizagem no contexto escolar, inicia dizendo que as pessoas estão cada vez mais conectadas e que a nossa sociedade precisa estar inter-relacionada por redes comunicativas, sejam elas sociais ou profissionais, por exemplo, e essas mudanças, conforme o autor, fazem com que sejam necessárias transformações na educação ou, sobretudo no processo de ensino e aprendizagem do aluno, esteja ele no ensino básico ou superior. O autor cita Pimenta e Anastasiou (2002) para se referir ao ensino tradicional; repetitivo, no qual o aprendizado é medido pelo volume de conhecimentos, memorizações e repetições expressas em avaliações. Para tal, o autor apresenta pesquisas nesse capítulo, evidenciando a desmotivação do aluno em relação ao processo de aprendizagem tradicional. Assim, mostra estatisticamente, a partir de gráficos, a comparação entre a frequência cardíaca dos alunos nas aulas tradicionais e nas aulas que as metodologias ativas de aprendizagem foram introduzidas. Camargo salienta que, ao se proporcionar com que os alunos se sintam parte do processo, sensação essa aliada à aplicação de estratégias de metodologias ativas de aprendizagem baseadas em resolução de problemas, aumenta-se consideravelmente as possibilidades para a sua aprendizagem, quando comparada ao método tradicional. Trata-se de um importante capítulo, no qual o leitor pode ter a oportunidade de analisar os gráficos e compará-los. Hoje é importante 
desenvolver no aluno competências e habilidades, retendo maiores conhecimentos, por meio de práticas interativas e colaborativas de ensino, como pontua o autor Dale (1969), mencionado no capítulo.

Na parte II, intitulada “Estratégias pedagógicas para o aprendizado ativo”, Fausto Camargo e Thuinie Daros descrevem detalhadamente quarenta e três estratégias, organizadas de modo sequencial, abrangendo as competências e habilidades previstas em currículo, bem como sugestões e recomendações de aplicação e modelos de questionários, fichas, planilhas etc. Os autores ainda sugerem determinados sites, jogos e aplicativos baseados nas metodologias ativas e nas novas tecnologias para serem desenvolvidas em sala de aula. A segunda parte do livro é de grande relevância e importância, pois nos apresenta sugestões de materiais que podem ser trabalhados de maneira inovadora na sala de aula.

O livro aborda as metodologias ativas de aprendizagem e o método tradicional, de forma séria e crítica, destacando possibilidades criativas para se trabalhar uma sala de aula, como, por exemplo, a partir do uso das tecnologias digitais de informação e comunicação. Por fim, encontra-se nessa obra subsídios necessários e fundamentais para uma prática pedagógica voltada às necessidades atuais da educação, conforme pontua a nova Base Nacional Comum Curricular (BNCC), além disso, apresenta-se esclarecimentos e valoriza-se os diferentes recursos existentes e a necessidade de se estimular a autonomia dos alunos, a partir de iniciativas diferenciadas favoráveis à mediação entre os pares e a sala de aula inovadora.

\section{Referências}

DALE, E. Edition of audio-visual methods in teaching. 3. ed. New York: Dryden, 1969.

DEWEY, J. Experiência e educação. 2. ed. São Paulo: Nacional, 1976.

PIMENTA, S. G.; ANASTASIOU, L. G. C. Docência no ensino superior. São Paulo: Cortez, 2002.

TERRA, J. C. C. (Org.). Inovação: quebrando paradigmas para vencer. São Paulo: Saraiva, 2007.

\section{Ingrid Santella Evaristo}

Graduada em Licenciatura Plena em Matemática e Pedagogia pela Universidade Nove de Julho (Uninove). Lato Sensu em Gestão Financeira e Orçamentária pela Universidade Nove de Julho (Uninove). Mestranda do Programa de Mestrado em Gestão e Práticas Educacionais (PROGEPE/ Uninove) pela Universidade Nove de Julho (Uninove). Professora de Matemática na Secretaria da Educação do Estado de São Paulo. E-mail: isantella@hotmail.com.

\section{Adriana Aparecida de Lima Terçariol}

Pós-doutorado pela Universidade Aberta - Portugal junto ao Departamento de Educação e Ensino a Distância. Doutora em Educação e Currículo pela Pontifícia Universidade Católica 
de São Paulo. Mestre e Pedagoga pela Faculdade de Ciências e Tecnologia Unesp/Campus de Presidente Prudente/SP. Docente no Curso de Pedagogia (Presencial/Distância) e Programas de Pós-Graduação em Educação, vinculados à Universidade Nove de Julho (UNINOVE-SP), e-mail: atercariol@gmail.com.

Recebido em: 24.12.2018

Aprovado em: 25.02.2019 